\title{
LIQUID-PHASE MICROEXTRACTION FOR SIMULTANEOUS CHROMATOGRAPHIC ANALYSIS OF THREE ANTIDEPRESSANT DRUGS IN PLASMA
}

\author{
Carlos Eduardo Dobrovolskni Porto, Patrícia Penido Maia, Daniela Fernanda de Freitas, Rafhaella Carolina Cedro Araújo, \\ Maria Elisa Pereira Bastos de Siqueira e Isarita Martins* \\ Faculdade de Ciências Farmacêuticas, Universidade Federal de Alfenas, Av. Gabriel Monteiro da Silva, 700, 37130-000 \\ Alfenas - MG, Brasil \\ Álvaro José dos Santos-Neto \\ Instituto de Química de São Carlos, Universidade de São Paulo, CP 780, 13560-970 São Carlos - SP, Brasil
}

Recebido em 26/1/11; aceito em 20/5/11; publicado na web em 22/7/11

\begin{abstract}
A method using Liquid Phase Microextraction for simultaneous detection of citalopram (CIT), paroxetine (PAR) and fluoxetine (FLU), using venlafaxine as internal standard, in plasma by high performance liquid chromatography with fluorescence detection was developed. The linearity was evaluated between 5.0 and $500 \mathrm{ng} \mathrm{mL}^{-1}(\mathrm{r}>0.99)$ and the limit of quantification was $2.0,3.0$ and $5.0 \mathrm{ng} \mathrm{mL}^{-1}$ for CIT, PAR and FLU, respectively. Therefore, it can be applied to therapeutic drug monitoring, pharmacokinetics or bioavailability studies and its advantages are that it necessary relatively inexpensive equipment and sample preparation techniques.
\end{abstract}

Keywords: LPME; antidepressants; HPLC-FL.

\section{INTRODUCTION}

Depression is a disorder that affects the part of the brain responsible for mood regulation, and antidepressants are used to treat this disorder and elevate a patient's mood. ${ }^{1}$ Controlling the efficacy of depression medication has been the subject of investigation after the discovery of the antidepressant properties of monoamine oxidase inhibitors (MAOIs), tricyclic antidepressants (TCA) and selective serotonin reuptake inhibitors (SSRI). These discoveries have led to progress in the treatment and understanding of possible mechanisms underlying depressive disorders. ${ }^{2}$ MAOIs and TCAs, although very effective, have undesirable side effects caused by the lack of specificity of their pharmacological action, and they are potentially lethal in cases of overdose. ${ }^{1,2}$

The SSRIs, citalopram (CIT), fluoxetine (FLU), fluvoxamine, paroxetine (PAR) and sertraline, are the result of research to find drugs as effective as TCAs, but with fewer problems with tolerability and safety. SSRIs inhibit serotonin reuptake potently and selectively, resulting in the increase of serotonergic neurotransmission. Although they share the primary mechanism of action with TCAs, SSRIs are structurally distinct, with marked differences in the pharmacokinetic and pharmacodynamic profile. Sertraline and paroxetine are the most potent reuptake inhibitors. The relative potency of sertraline in inhibiting dopamine uptake differentiates it pharmacologically from other SSRIs. Citalopram and fluoxetine are racemic mixtures of chiral forms that have different pharmacokinetic and pharmacodynamic profiles. The fluoxetine metabolite is long acting and is pharmacologically active. SSRIs also have different pharmacokinetic profiles, including half-life, linear pharmacokinetics versus the non-linear effect of age on its clearance, and its potential to inhibit the drug-metabolising isoenzyme, cytochrome P450 (CYP). These differences underscore that the pharmacological and pharmacokinetic clinical differences have become increasingly important for SSRIs. ${ }^{2}$ Figure 1 shows the chemical structures of the SSRIs studied.

Several methods have been proposed for the detection of antide-

\footnotetext{
*e-mail: isarita@unifal-mg.edu.br
}<smiles>CNCCC(Oc1ccc(C(F)(F)F)cc1)c1ccccc1</smiles><smiles>CCOCCCOc1ccc2c(c1)OCO2</smiles><smiles>CN(C)CCCC1(c2ccc(F)cc2)OCc2cc(C#N)ccc21</smiles>

citalopram
Figure 1. Chemical structures of the antidepressants: fluoxetine, citalopram and paroxetine

pressants in biological fluids for therapeutic monitoring, bioavailability studies and toxicological purposes, but the sample preparation is a critical step for isolating the target analytes. The choice of a particular sample preparation process is based on the physico-chemical constituents of the sample (analytes, interferences and matrices) such as polarity, solubility and chemical and thermal stability. It is also important to know or estimate the concentration of the analytes and potential interferences, the characteristics of the equipment available and the existence of an official methodology and the availability of skilled personnel. ${ }^{3}$

The techniques most commonly employed in the extraction and/-or pre-concentration of these drugs in biological fluids are protein precipitation, liquid-liquid extraction (LLE) ${ }^{4-6}$ and solid phase extraction $(\mathrm{SPE})^{7,8}$ prior the chromatographic analysis. Non-exhaustive techniques based on the principles of balance, pre-equilibrium and permeation can also be used. The non-exhaustive techniques are fundamentally similar to the exhaustive techniques; however, the 
capacity of the extraction phase is small and, in most cases, is not sufficient to remove most of the analytes present in the matrix. ${ }^{3}$

The determination of SSRIs is possible using high performance liquid chromatography (HPLC) with ultra-violet (UV) and fluorescence (FL) or gas chromatography (GC) with nitrogen-phosphorus detectors (NPD). ${ }^{9}$ The simultaneous determination of CIT, PAR and FLU in plasma and blood samples by solid phase extraction (SPE) and HPLC-UV/FL has been studied, ${ }^{10}$ while a method using SPE and HPLC-MS was previously used for the determination of FLU, CIT, PAR and VEN in plasma samples. ${ }^{8}$

Liquid-liquid microextraction (Liquid Phase Microextraction, LPME) has gained attention in recent years, mainly as a technique for sample preparation for chromatographic and electrophoretic analysis of xenobiotics. Hollow fibre liquid-phase microextraction (HF-LPME) is a relatively new technique for sample preparation, introduced in 1999 which produces pre-concentrated analytes and provides an efficient "clean-up" effect. ${ }^{11}$ In this technique, the principles of LLE are miniaturised, and the analytes are extracted from small volumes of biological material through an organic solvent immobilised in the pores of a hollow polypropylene fibre. Then the analytes migrate to a small volume of acceptor phase that is placed inside fibre. ${ }^{12,13}$ Recently, a method using a three-phase LPME coupled to an HPLC-fluorescence detector to analyse fluoxetine and its active metabolite, norfluoxetine, in plasma samples was published. ${ }^{14}$ However, it is important to develop methods that are able to detect multiple compounds for application in toxicological and forensic analysis, as a screening method for drug abuse cases. Therefore, the aim of this study was to develop a method to detect fluoxetine, citalopram and paroxetine in plasma samples using LPME coupled to liquid chromatographic analysis.

\section{EXPERIMENTAL}

\section{Chemicals}

HPLC-grade acetonitrile was purchased from Vetec (Rio de Janeiro, Brazil). HPLC-grade methanol and ethanol were obtained from J.T. Baker (Philipsburg, USA). Analytical-grade solvents were utilised, including $n$-octanol and $n$-hexyl ether from Sigma-Aldrich (St. Louis, USA), $n$-hexane from Mallinckrodt (Paris, USA), and toluene from Vetec (Rio de Janeiro, Brazil). Other chemicals that were used include the following: sodium acetate from Proquimios (Rio de Janeiro, Brazil), acetic acid and sodium chloride from Impex (Contagem, Brazil), ammonium acetate from Ecibra (São Paulo, Brazil), sodium dihydrogen phosphate from Dinâmica (Diadema, Brazil), sodium hydroxide from Labsynth (Diadema, Brazil), hydrochloric acid from Vetec (Rio de Janeiro, Brazil) and perchloric acid from Reagen (Rio de Janeiro, Brazil). All aqueous solutions were prepared with purified water, which was obtained using a Milli-Q apparatus (Millipore Corporation, Bedford, USA).

\section{Standard and stock solutions}

Citalopram (CIT) and fluoxetine (FLU), purity > 98\%, were purchased from Sigma- Aldrich ${ }^{\circledR}$ (St. Louis, USA). Paroxetine (PAR) and venlafaxine (VEN) (internal standard) were purchased from Wyeth $^{\circledR}$ (Madison, EUA). Standard stock solutions of antidepressants were prepared by dissolving $100 \mathrm{mg}( \pm 0.1 \mathrm{mg})$ of each compound in $100 \mathrm{~mL}$ of methanol. The solutions were stored at $-20^{\circ} \mathrm{C}$ between experiments. Standard working solutions were prepared daily by diluting the standard stock solution to concentrations of $0.5,1.5,5$, 10,25 and $50 \mathrm{ng} \mathrm{mL}^{-1}$ and VEN to $50 \mathrm{ng} \mathrm{mL}^{-1}$.

\section{HPLC conditions}

Sample analyses were performed on a Shimadzu model LC-10AV (Kyoto, Japan) HPLC that was equipped with a LC-10AD pump, a CTO-10AS VP column oven, a SIL-10 AF automatic injector $(50 \mu \mathrm{L}$ loop), a SPD-10AVP UV detector and a RF-10AXL fluorescence detector. The chromatographic conditions established included a LiChrospher 60 RP-Select B reverse-phase column (125 x 4 mm, $5 \mu \mathrm{m}$ particle size) from Merck (Darmstadt, Germany), operating at $25^{\circ} \mathrm{C}$. The mobile phase consisted of a $0.005 \mathrm{~mol} \mathrm{~L}^{-1}$ sodium acetate buffer $(\mathrm{pH} 4.5)$ and acetonitrile in a 50:50 (v/v) mixture at a $0.6 \mathrm{~mL} \mathrm{~min}^{-1}$ flow rate. The fluorescence detector was set at $230 \mathrm{~nm}$ (excitation) and $290 \mathrm{~nm}$ (emission) for CIT and FLU, at $294 \mathrm{~nm}$ (excitation) and $330 \mathrm{~nm}$ (emission) for PAR.

\section{Sampling}

Drug-free human plasma samples used for LPME optimization and method validation were provided by healthy volunteers. Real plasma samples were collected from 3 patients undergoing treatment with CIT at doses varying between 10 and $20 \mathrm{mg} \mathrm{day}^{-1}, 3$ patients undergoing treatment with FLU at doses varying between 20 and 40 $\mathrm{mg} \mathrm{day}^{-1}$ and 2 patients undergoing treatment with PAR at doses of $20 \mathrm{mg} \mathrm{day}^{-1}$. Blood samples from these volunteers were collected immediately prior to the drug administration (minimum plasma concentration). All of the patients signed a written and informed consent form prior to the investigation and the study was approved by the Ethics Committee of the Federal University of Alfenas (protocol number 23087.001196/2008-16). All of the blood samples were collected in Vacutainer heparinised tubes (Becton Dickinson, Meylan, France). These were subsequently centrifuged for $15 \mathrm{~min}$ at $560 \times \mathrm{g}$, and the plasma samples were stored at $-20{ }^{\circ} \mathrm{C}$ for no longer than 2 weeks.

\section{Sample preparation}

The LPME system consisted of a plasma solution (donor), extracting solvent and acceptor solution. A $1 \mathrm{~mL}$ sample (with $10 \mu \mathrm{L}$ of a $50 \mathrm{ng} \mathrm{mL}^{-1}$ of a VEN solution) was placed in a conventional 5 $\mathrm{mL}$ vial (Supelco, Bellefonte, USA), and its $\mathrm{pH}$ was adjusted using $100 \mu \mathrm{L}$ of a $5 \mathrm{~mol} \mathrm{~L}^{-1}$ sodium hydroxide solution. The sample was diluted with ultrapure water to a total volume of $5.0 \mathrm{~mL}$. All of the LPME experiments were performed using Accurel Q3/2 polypropylene hollow fibre membranes (600 $\mu$ m I.D., $200 \mu \mathrm{m}$ wall thickness and $0.2 \mu \mathrm{m}$ pore size) from Membrana (Wuppertal, Germany). These membranes were in a " $U$ " format, as described previously. ${ }^{12,14}$ The hollow fibre was manually cut to $7 \mathrm{~cm}$ and then employed for LPME. Syringes ( 25 and $50 \mu \mathrm{L}$ ) with $22 \mathrm{~s}$ gauge bevelled tip needles (Hamilton, Reno, USA) were used to connect the hollow fibre ends. One syringe served to introduce the acceptor solution, while another was used for collecting the final extract. Prior to extraction, the extracting solvent was immobilised in the pores of the hollow fibre. This immobilisation was performed by dipping the fibre into $n$-hexyl ether for $10 \mathrm{~s}$, followed by immersion in an ultrasonic water bath for $15 \mathrm{~s}$ to remove excess solvent. Subsequently, $20 \mu \mathrm{L}$ of the acceptor solution was injected into the hollow fibre and the assembly was immersed into the sample directly. During extraction, the samples were stirred using $1 \mathrm{~cm}$ magnetic bars (Sigma-Aldrich, St. Louis, USA). After extraction, $20 \mu \mathrm{L}$ of the acceptor solution was retracted into a $50 \mu \mathrm{L}$ microsyringe and diluted to $100 \mu \mathrm{L}$ with the mobile phase. An aliquot of $50 \mu \mathrm{L}$ was injected into the chromatographic system. Three samples were processed simultaneously. 


\section{Confidence parameters}

The method was validated in-house using the following performance criteria: selectivity, linearity and linear range, sensitivity, limit of quantification, intra-assay and inter-assay precision and accuracy, and extraction efficiency.

Selectivity of the method was evaluated by analysing blank and spiked plasma samples that were obtained from six individuals, four normal samples, one haemolysed and another lipaemic. The chromatographic behaviour of other drugs that were added to the plasma and submitted to the method (i.e., diazepam, nordiazepam, amitriptyline, clomipramine, clonazepam, chlordiazepoxide, chlorpromazine, fenacetine, lorazepam, caffeine and nicotine) was also verified.

The linearity, linear range and sensitivity were established through the analytical curve obtained by 6 replicates per concentration, at 6 concentration levels between the limit of quantification (LOQ) and $500 \mathrm{ng} \mathrm{mL}^{-1}$. The sensitivity is the slope of the analytical curve. The LOQ was determined at a signal-to-noise ratio of $10(\mathrm{~S} / \mathrm{N}=10)$.

The intra-assay precision (repeatability) of the method, expressed as the relative standard deviation of the peak area measurements $(n=6)$, was evaluated through the results obtained by the method operating over one day, under the same conditions, using solutions of each analyte at three concentration levels, 5, 50 and $250 \mathrm{ng} \mathrm{mL}^{-1}$ (50 ng mL $\mathrm{mL}^{-1}$ of VEN). The inter-assay precision was determined for the same 3 concentration levels, three replicates, and the analyses were performed for 3 days.

Accuracy was established by spiking the plasma samples with 15, 50 and $250 \mathrm{ng} \mathrm{mL} \mathrm{mL}^{-1}$ ( $n=3$ per concentration). After LPME extraction and chromatographic analysis, results were compared to the theoretically added values. Recovery (extraction efficiency) was calculated from the plasma samples spiked with 15,50 and $250 \mathrm{ng}$ $\mathrm{mL}^{-1}(\mathrm{n}=3$ /each concentration). These recoveries were submitted for analysis by the studied method (LPME/HPLC-FL) and the results were compared with those obtained by direct acceptor phase addition of the same analyte quantities.

\section{RESULTS AND DISCUSSION}

The methods of antidepressants analysis in plasma must present high detectability to allow detection of low quantities of analytes (ng $\mathrm{mL}^{-1}$ ). The HPLC with FL detection employing LPME can be used in routine analysis of these drugs since it is a simple, inexpensive and reliable alternative to others sample preparation techniques.

\section{Chromatographic conditions}

The retention times obtained in the chromatographic conditions established were $7.52 \mathrm{~min}$ (VEN), $10.32 \mathrm{~min}$ (CIT), $14.81 \mathrm{~min}$ (PAR) and $17.15 \mathrm{~min}$ (FLU). System suitability parameters of the chromatographic analysis (Table 1), including adequate efficiency (number of plates, $N$, above 2000), resolution ( $\mathrm{Rs} \geq 2$ ), tailing factor (TF $\leq$ $2)$ and capacity factor $\left(k^{\prime}>2\right)$, were adequate according to US-FDA recommendations. ${ }^{15,16}$ Figure 2 shows the chromatograms of the drugs extracted from plasma by LPME using the optimised chromatographic conditions established for this analysis. These conditions, in addition to increasing the method sensitivity, result in better method selectivity. Fluorescence spectroscopy was used as a sensitive and selective detection method for compounds that fluoresce. ${ }^{17}$ In this study, this detector increased the peak sensitivity.

\section{LPME conditions}

In this study, LPME was optimised for citalopram, fluoxetine and paroxetine using the parameters evaluated in a previous study. ${ }^{14}$ The three-phase system can ionise acidic and basic analytes. The pka value of CIT, PAR and FLU is $9.6,10.3$ and 10.05, respectively, ${ }^{18}$ and the $\mathrm{pH}$ of plasma sample solutions is known to play an essential role in the extraction of these drugs. They should be in their neutral form, making them extractable by the organic solvent immobilised in the fibre pore. The acceptor phase for trapping the analyte should be acidic to guarantee prevalence of the ionised form. This form does not diffuse back into the organic solvent. ${ }^{14}$
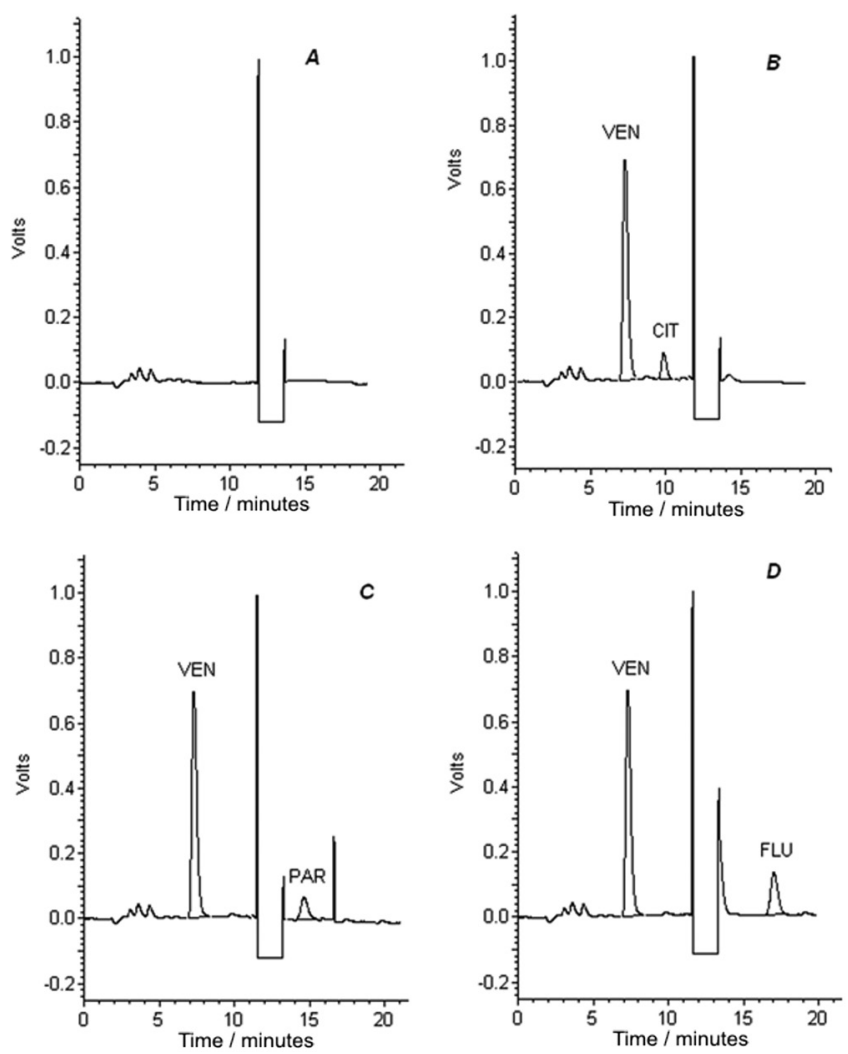

Figure 2. Characteristic chromatograms: (A) blank sample; (B) patient treated with $20 \mathrm{mg}^{\text {day-1 }}$ citalopram; (C) patient treated with $20 \mathrm{mg}^{\text {day-1 }}$ paroxetine; (D) patient treated with $20 \mathrm{mg}$ day-1 fluoxetine

Table 1. System suitability parameters to developed method to simultaneous analysis of antidepressants in plasma samples

\begin{tabular}{lccccc}
\hline Drugs $^{\mathrm{a}}$ & Retention time & Number of plates $(\mathrm{N})$ & Resolution $^{\mathrm{b}}(\mathrm{Rs})$ & Tailing factor $(\mathrm{TF})$ & Capacity factor $\left(k^{\prime}\right)$ \\
\hline VEN & 7.52 & 2535.20 & - & 1.30 & 6.51 \\
CIT & 10.32 & 3946.87 & 4.31 & 1.23 & 9.20 \\
PAR & 11.81 & 4547.11 & 2.61 & 1.19 & 10.85 \\
FLU & 17.15 & 6209.66 & 6.57 & 1.15 & 15.98 \\
\hline
\end{tabular}

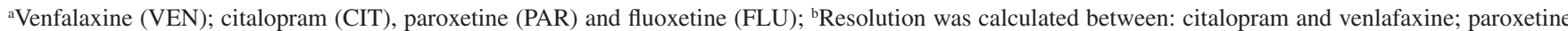
and citalopram; fluoxetine and paroxetine. 
In general, the chosen organic solvent must be immiscible with the acceptor and donor phase (sample), must be compatible with the membrane, must be of low volatility and must present affinity for the analyte to be tested. ${ }^{19-22}$ According to the results, $n$-hexyl ether resulted in satisfactory extraction efficiency. The $\mathrm{pH}$ adjustment of the plasma sample is an essential step in this system to guarantee the highest extraction coefficient and to increase the efficiency. ${ }^{20}$ A $\mathrm{pH}$ value of 14, adjusted by $2 \mathrm{~mol} \mathrm{~L}^{-1} \mathrm{NaOH}$, resulted in the highest efficiency.

In LPME, sufficient time is needed to permit partitioning of the analyte between the two liquid phases because it is an equilibrium system. An exposure time of $40 \mathrm{~min}$ was selected because it provides a satisfactory efficiency and can be applied in laboratory routine. Magnetic bars can cause cross contamination of samples and can lead the formation of air bubbles that may adhere on the fibre surface, accelerating the evaporation of the solvent. ${ }^{23}$ This problem was avoided by maintaining a moderate and constant agitation rate for all samples during the procedure. The extraction kinetics can be accelerated by shaking the sample, which facilitates the diffusion of the analytes from the donor phase through the extraction solution to the acceptor solution. ${ }^{24}$ The stirring speed of $1400 \mathrm{rpm}$ was selected because a higher velocity introduced more inaccuracy in the analyses.

When using the three-phase LPME system for the extraction of basic drugs, the $\mathrm{pH}$ of the acceptor solution should be in the acidic range, thus ensuring the protonation of the analytes and avoiding losses of the same solution for the donor. ${ }^{13,25}$ Among the acids studied, a $20 \mathrm{mmol} \mathrm{L}^{-1} \mathrm{HCl}$ solution of $\mathrm{pH} 2.0$ showed the greatest recovery of the analytes. This acid is the most quoted in literature for use as the acceptor solution. . $^{13,26-29}$

The drug-protein interactions are usually responsible for the low recovery values. Because of this interaction, it is common to add an organic solvent in the donor solution (sample) to suppress the drug-protein bonds. ${ }^{13}$ Methanol gave the best response increasing the peak area around 16.6 times. This alcohol has the ability to disrupt hydrophobic and polar interactions between the analyte and the proteins. ${ }^{12,30,31}$ However, the addition of methanol interfered with the accuracy of the method, reducing the repeatability of the extraction.

The optimum LPME conditions established for CIT, PAR and FLX extraction from plasma samples, based on the results discussed previously, are the following: $n$-hexyl ether as the organic solvent; addition of a $1 \mathrm{~mL}$ plasma sample with $100 \mu \mathrm{L}$ of $2 \mathrm{~mol} \mathrm{~L}^{-1} \mathrm{NaOH}$, with subsequent dilution to $5 \mathrm{~mL}$ with purified water; $40 \mathrm{~min}$ extraction time with a stirring speed of $1400 \mathrm{rpm}$; and $20 \mu \mathrm{L}$ of $20 \mathrm{mmol}$ $\mathrm{L}^{-1} \mathrm{HCl}$ as the acceptor phase. The selectivity of the LPME technique and of the method developed is shown in Figure 2A: a blank sample was analysed and no interfering peaks from endogenous compounds were observed in the chromatogram. Blank matrices added to the other drugs were also tested and none of these drugs presented any response in the fluorescence detector used.

\section{Confidence parameters}

The method was validated for the determination of CIT, PAR and FLU in plasma samples, using VEN as an internal standard. The linearity, linear range, sensitivity and limit of quantification were obtained by calibration (Table 2). The linearity was tested using a pure error lack of fit test with a simple regression, which was not significant at the $5 \%$ level. The limit of quantification of the method was 2.0, 3.0 and $5.0 \mathrm{ng} \mathrm{mL}^{-1}$ for CIT, PAR and FLU, respectively. The linear range of concentrations for this method can be satisfactorily applied to therapeutic drug monitoring, pharmacokinetics or biodisponibility studies of these drugs. Intra- and inter-assay precision was assessed at three concentration levels, and the results are shown in Table 3.

Table 2. Validation parameters obtained from the calibration in plasma samples by the method developed

\begin{tabular}{lcccc}
\hline Drug & $\begin{array}{c}\text { Linear } \\
\text { range }\left(\mathrm{ng} \mathrm{mL}^{-1}\right)\end{array}$ & Sensitivity & Intercept & Linearity (r) \\
\hline Citalopram & $2.0-500$ & 0.0072 & 0.0103 & 0.9992 \\
Fluoxetine & $5.0-500$ & 0.003 & 0.007 & 0.9975 \\
Paroxetine & $3.0-500$ & 0.006 & 0.054 & 0.9985 \\
\hline
\end{tabular}

Table 3. Intra- and inter-assay precision, evaluated by the relative standard deviation, for the determination of citalopram (CIT), fluoxetine (FLU) and paroxetine (PAR) in plasma samples by the method developed

\begin{tabular}{|c|c|c|c|}
\hline \multirow[b]{2}{*}{ Drug } & \multicolumn{3}{|c|}{${ }^{\mathrm{a}} \mathrm{RSD}(\%)$} \\
\hline & $5 \mathrm{ng} \mathrm{mL}^{-1}$ & $50 \mathrm{ng} \mathrm{mL}^{-1}$ & $250 \mathrm{ng} \mathrm{mL}^{-1}$ \\
\hline \multicolumn{4}{|l|}{ CIT } \\
\hline Intra-assay precision & 6.8 & 8.2 & 6.7 \\
\hline Inter-assay precision & 2.0 & 4.5 & 5.7 \\
\hline \multicolumn{4}{|l|}{ FLU } \\
\hline Intra-assay precision & 3.6 & 5.5 & 2.9 \\
\hline Inter-assay precision & 6.6 & 4.8 & 4.9 \\
\hline \multicolumn{4}{|l|}{ PAR } \\
\hline Intra-assay precision & 5.8 & 6.3 & 6.6 \\
\hline Inter-assay precision & 3.5 & 4.0 & 5.2 \\
\hline
\end{tabular}

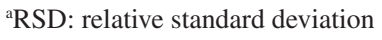

All values of the relative standard deviations were below $10 \%$ and are, therefore, acceptable for the analyses of biological samples. Accuracy was evaluated by comparing the theoretical concentrations to the obtained concentrations. Samples containing the citalopram, fluoxetine and paroxetine were analysed in three replicates (Table 4). The LPME is a non- exhaustive technique, meaning that the analyte is transferred gradually to the acceptor solution until its concentration is constant. ${ }^{22,32,33}$ Low recovery in LPME, compared to LLE extraction, is a common problem due to the micro-scale characteristic of the technique. ${ }^{24}$ Furthermore, it should be taken into account that the extraction procedure results in high enrichment values. This method also enables a direct injection of the total amount of the acceptor phase material. ${ }^{22}$

Table 4. Accuracy and extraction efficiency for the determination of citalopram (CIT), fluoxetine (FLU) and paroxetine (PAR) in plasma samples by the method developed

\begin{tabular}{lccc}
\hline Drug & $15 \mathrm{ng} \mathrm{mL}^{-1}$ & $50 \mathrm{ng} \mathrm{mL}^{-1}$ & $250 \mathrm{ng} \mathrm{mL}^{-1}$ \\
\hline CIT & & & \\
Accuracy (\%) & 94.2 & 88.5 & 99.8 \\
Extraction efficiency (\%) & 75.9 & 78.4 & 78.5 \\
FLU & & & \\
Accuracy (\%) & 99.6 & 90.3 & 88.7 \\
Extraction efficiency (\%) & 67.0 & 64.9 & 66.1 \\
PAR & & & \\
Accuracy (\%) & 100.3 & 88.9 & 90.3 \\
Extraction efficiency (\%) & 67.5 & 71.3 & 70.7 \\
\hline
\end{tabular}

\section{Application of the method}

The proposed method was applied to analyse plasma samples from human patients treated with CIT, PAR and FLU. Plasma con- 
centrations of citalopram are proportional to the doses administered with linear pharmacokinetics. This drug class, compared to other SSRIs, shows less binding to plasma proteins. The therapeutic range found in the literature is 40 to $200 \mathrm{ng} \mathrm{mL}^{-1}$. $^{2,10}$ Figure $2 \mathrm{~B}$ shows the chromatogram of the analysis of one patient. It is interesting to note that this patient started treatment with citalopram about 1 week before blood collection and had previously used paroxetine. Thus, it was possible to identify traces of paroxetine in the plasma (3.57 $\mathrm{ng} \mathrm{mL} \mathrm{L}^{-1}$ ), demonstrating the satisfactory sensitivity of the method and its breadth in the detection of both drugs simultaneously. Table 5 shows the values of PAR in the plasma of two patients undergoing treatment with this drug, and Figure $2 \mathrm{C}$ shows a characteristic chromatogram. The therapeutic range for PAR in plasma is 20 to $190 \mathrm{ng} \mathrm{mL}{ }^{-1}{ }^{2,10}$ The plasma levels of fluoxetine in three patients are shown in Table 5, and a chromatogram of one of these patients is shown in Figure 2D. The FLU has nonlinear pharmacokinetics; the plasmatic concentration dose is not proportional to that dose. ${ }^{34}$ The optimal therapeutic range for FLU is not established with certainty, although plasmatic concentrations correlate better with the patient's clinical response. Values between 50 and $500 \mathrm{ng} \mathrm{mL}^{-1}$ are cited as the optimal therapeutic range, considering the different dosages of the drug. ${ }^{35}$

Table 5. Citalopram, fluoxetine and paroxetine in plasma samples from patients treated with the drugs analysed by the proposed method

\begin{tabular}{lcc}
\hline Sample & Concentration $\left(\mathrm{ng} \mathrm{mL}^{-1}\right)$ & Dose $\left(\mathrm{mg} \mathrm{day}^{-1}\right)$ \\
\hline Citalopram & & 20 \\
C1 & 67.91 & 20 \\
C2 & 91.61 & 10 \\
C3 & 52.66 & \\
Fluoxetine & & 20 \\
F1 & 116.14 & 20 \\
F2 & 79.87 & 40 \\
F3 & 187.98 & \\
Paroxetine & & 20 \\
P1 & 41.31 & 20 \\
P2 & 71.17 &
\end{tabular}

\section{CONCLUSIONS}

A suitable LPME extraction followed by HPLC-FL method was developed and validated for the simultaneous determination of citalopram, fluoxetine, paroxetine and venlafaxine (internal standard, I.S.) in human plasma. This method provides a good alternative to existing methods for analyzing antidepressants employing LPME. The major advantage of this method over similar methods is that it is performed in isocratic mode and it is free from endogenous compounds. In addition, it is necessary relatively inexpensive equipment and sample preparation techniques, which are usually employed in routine analyses of drugs in biological specimens. Its wide linear range, precision and accuracy allow application to biomedical and toxicological analysis of these drugs in plasma.

\section{ACKNOWLEDGEMENTS}

This research was supported by the National Council for Scientific and Technological Development (CNPq)/Brazil and by Fundação de Amparo à Pesquisa do Estado de Minas Gerais (FAPEMIG)/Brazil (process number CDS-PPM-00055-09).

\section{REFERENCES}

1. Scippa, A. M. A. M.; Oliveira, I. R. In Farmacologia; Silva, P., ed.; Guanabara Koogan: Rio de Janeiro, 2006, chap. 36.

2. Moreno, R. A; Moreno, D. H.; Soares, M. B. M.; Rev. Bras. Psiquiatr. 1999, $21,24$.

3. Pawliszyn, J.; Sampling and sample preparation for field and laboratory: Fundamentals and New Directions in Sample Preparation, $2^{\text {nd }}$ ed., Elsevier Science: Amsterdam, 2002.

4. Fontanille, P.; Jourdil, N.; Villier, G. T. B.; J. Chromatogr., B: Anal. Technol. Biomed. Life Sci. 1997, 692, 337.

5. Gatti, G.; Bonomi, I.; Marchiselli, R.; Fatorre, C.; Spina, E.; Scordo, G.; Pacific, R.; Peruca, E.; J. Chromatogr., B: Anal. Technol. Biomed. Life Sci. 2003, 784, 375.

6. Ulrich, S.; J. Chromatogr., B: Anal. Technol. Biomed. Life Sci. 2003, 78, 481.

7. Molander, P.; Thomassen, A.; Kristoffersen, L.; Greibokk, T.; Ludanes, E.; J. Chromatogr., B: Anal. Technol. Biomed. Life Sci. 2002, 766, 77.

8. Juan, H.; Zhiling, Z.; Huande, L.; J. Chromatogr., B: Anal. Technol. Biomed. Life Sci. 2005, 820, 33.

9. Eap, C. B.; Baumann, P.; J. Chromatogr., B: Anal. Technol. Biomed. Life Sci. 1996, 686, 51.

10. Kristoffersen, K.; Bugge, A.; Lundanes, E.; Slørdal, L.; J. Chromatogr., B: Anal. Technol. Biomed. Life Sci. 1999, 734, 229.

11. Pedersen-Bjergaard, S.; Rasmussen, K. E.; Anal. Chem. 1999, 71, 2650.

12. Santana, F. J. M.; Oliveira, A. R. M.; Bonato, P. S.; Anal. Chim. Acta 2005, $549,96$.

13. Oliveira, A. R. M.; Magalhães, I. R. S.; Santana, F. J. M.; Bonato, P. S.; Quim. Nova 2008, 31, 637.

14. Freitas, D. F.; Porto, C. E. D.; Vieira, E. P.; Siqueira, M. E. P. B.; J. Pharm. Biomed. Anal. 2010, 51, 170.

15. US FDA - United States Food and Drug Administration; Reviewer guidance Validation of chromatographic methods, FDA Center for Drug Evaluation and Research (CDER), Rockville, 1994.

16. Shabir, G. A. J.; J. Chromatogr., A 2003, 987, 57.

17. Maia, P. P.; Rath, S.; Reyes, F. G. R.; Food Chem. 2008, 109, 212.

18. Kwon, J-W; Armbrust, K. L.; Bull. Environ. Contam. Toxicol. 2008, 81, 128.

19. Müller. S.; Möder. M.; Schrader, S.; Popp. P.; J. Chromatogr., A 2003, 985 , 99.

20. Pedersen-Bjergaard, S.; Rasmussen, K. E.; J. Chromatogr., B: Anal. Technol. Biomed. Life Sci. 2005, 817, 3 .

21. Flanagan, R. J.; Morgan, P. E.; Spencer, E. P.; Whelpton, R.; Biomed. Chromatogr. 2006, 20, 530.

22. Pedersen-Bjegaard, S.; Rasmussen, K. E.; J. Chromatogr., A 2008, 1184, 132.

23. Psillakis, E.; Kalogerakis, N.; Trends Anal. Chem. 2003, 22, 565.

24. Lord, H.; Pawliszyn. J.; J. Chromatogr., A 2000, 902, 17.

25. Ugland, H. G.; Krogh, M.; Reubsaet, L.; J. Chromatogr., B: Anal. Technol. Biomed. Life Sci. 2003, 98, 127.

26. Halvorsen, T. G.; Pedersen-Bjergaard, S.; Rasmussen, K. E.; J. Chromatogr., B: Anal. Technol. Biomed. Life Sci. 2001, 760, 219.

27. Halvorsen, T. G.; Pedersen-Bjergaard, S.; Reubsaet, J. L. E.; Rasmussen, K. E.; J. Sep. Sci. 2003 26, 1520.

28. Yang, C.; Guo, L.; Liu, X.; Zhang, H.; Liu, M.; J. Chromatogr., A 2007, $1164,56$.

29. Pedersen-Bjergaard, S.; Rasmussen, K. E.; Electrophoresis 2000, 21, 579.

30. Ugland, H. G.; Kroagh, M.; Rasmussen, K. E.; J. Chromatogr., B: Anal. Technol. Biomed. Life Sci. 2000, 749, 85 .

31. Magalhães, I. R. S.; Bonato, P. S.; J. Pharm. Biomed. Anal. 2008, 46, 929.

32. Zhao, L.; Lee, H. K.; J. Chromatogr., A 2001, 919, 381.

33. Ho, T. S.; Pedersen-Bjergaard, S.; Rasmussen, K. E.; J. Chromatogr., A 2002, $963,3$.

34. Hiemke, C.; Härtter, S.; Pharmacol. Ther. 2000, 85, 11.

35. Baumann, P.; Clin. Pharmacokinet. 1996, 31, 444. 